\title{
Identification and Assessment of Ecological Sensitivity in Chishui River Basin Based on GIS
}

\author{
Haiying $\mathrm{Li}^{1, \mathrm{a}}$, Jia $\mathrm{Lu}^{1, \mathrm{~b}}$, Jiang $\mathrm{Yu}^{2}$ and Xinghua $\mathrm{Wu}^{3}$ \\ ${ }^{1}$ China Institute of Water Resources and Hydropower Research, 100038 Beijing, China \\ ${ }^{2}$ China Three Gorges Construction Management Co. Ltd, 100038 Beijing, China \\ ${ }^{3}$ China Three Gorges Corporation, 100038, Beijing, China
}

\begin{abstract}
In this paper, GIS and RS spatial analysis techniques were used to establish a system for identifying sensitive targets of terrestrial ecosystems in Chishui River Basin, and to identify protection targets of terrestrial ecosystems in different regions. The result shows that the assessment of habitat sensitivity in Chishui River Basin was dominated by non-sensitive areas and highly sensitive areas, which highly sensitive areas account for $60.43 \%$ of the basin area, mostly concentrated in the mountainous areas at the junction of Chishui City, Xishui County and Gulin County; non-sensitive areas account for $39.13 \%$ and are mosaically distributed with highly sensitive areas; mildly sensitive areas, moderately sensitive areas and extremely sensitive areas account for a total of about $0.5 \%$ of the basin area and are more scattered throughout the basin. The distribution is scattered. The moderately sensitive areas in the Chishui River Basin are more than $60.7 \%$ of the basin area, indicating that the habitats in the Chishui River Basin are generally sensitive and the ecologically sensitive targets are mainly wooded areas, which need to be protected.
\end{abstract}

\section{Introducton}

Chishui River is located in the upper reaches of the Yangtze River at the junction of Yunnan, Guizhou and Sichuan provinces. It is a larger tributary on the southern bank of the upper reaches of the Yangtze River. It originates in Zhenxiong County, northern Yunnan Province. Along the Sichuan-Guizhou border to Maotai Town, Guizhou, it goes through the city of Chishui with Natongzi River and Gulin River. Finally, it converges with Xishui River in Hejiang County, Sichuan Province and goes into the Yangtze River [1]. As one and only primary tributary which has no dam or water retaining projects to hinder the mainstream, the free flowing Chishui River is indeed a unique and valuable river in the upper reaches of the Yangtze River.

Chishui River is known as ecological river, beautiful river, beautiful wine river, and hero river [2]. In recent years, due to the impact of global climate change and human activities, the amount of water resources in the Chishui River Basin has decreased. The environment has deteriorated, soil erosion has aggravated, and the biodiversity is facing threats [2]. Therefore, ecological protection research should be carried out in the development process of Chishui River Basin.

Identification of ecologically sensitive targets is the basis and premise of ecological environmental protection.

a Corresponding author: lihaiy@iwhr.com and

b Corresponding author: lujia@iwhr.com
Spatial analysis of habitat sensitivity using GIS or RS can not only reflect the spatial distribution characteristics of the analyzed targets, but also calculate the overlay of different spatial attributes. The identified ecologically sensitive targets can be displayed intuitively on the map, which can play a better role in reference and guidance [3]. In order to provide scientific basis for the ecological civilization construction of the Chishui River Basin, this paper established the sensitive target identification system of the terrestrial ecosystem in the Chishui River Basin by using GIS and RS technologies and identified the protection targets of the terrestrial ecosystem in different regions and analyzed its ecological sensitivity.

The sensitivity analysis in our study was carried out based on GIS method. According to the literature survey, recent studies mostly involved geology, geomorphology, disaster prevention and other aspects [4, 5, 6]. For example, Chen Yang [7] selected topographic, geological and soil data for spatial analysis and superposition to determine the sensitivity threshold for geological disasters such as slope collapse, landslide and debris flow in the Dongxi Basin of Zhao 'an County. Ma Qi [8] analyzed the 10 -year change of ecological sensitivity of Wuding River in northern Shaanxi from three aspects of soil erosion sensitivity, habitat sensitivity and desertification 
sensitivity. The study area in this paper is Chishui River Basin, which is currently facing threats such as habitat destruction of biodiversity. Therefore, habitat sensitivity was selected as an evaluation index in this paper.

The types and quantity (i.e. area) of habitat play very important roles in protecting regional biodiversity, improving regional landscape quality and ecological environment quality, and have a direct impact on the stability and sensitivity of ecological environment. The distribution of habitat resources has strong regional traits. Different regions have different habitat resources, and their composition and structure characteristics are also diverse. Due to the great topography changes and different landform types in the watershed, the diversity of habitat types and their ecological sensitivity are also different.

Table 1. Habitat sensitivity assessment classification

\begin{tabular}{|c|c|c|c|c|c|}
\hline Item & insensitive & slightly sensitive & $\begin{array}{c}\text { moderately } \\
\text { sensitive }\end{array}$ & highly sensitive & $\begin{array}{c}\text { extremely } \\
\text { sensitive }\end{array}$ \\
\hline Habitat types & $\begin{array}{c}\text { Arable land, } \\
\text { construction } \\
\text { land, bare rock, } \\
\text { gravel, bare } \\
\text { land }\end{array}$ & $\begin{array}{c}\text { Garden, grassland, } \\
\text { herbaceous } \\
\text { swamp, alpine } \\
\text { meadow, alpine } \\
\text { sparse vegetation, } \\
\text { shrub desert }\end{array}$ & $\begin{array}{c}\text { Coniferous and broad- } \\
\text { leaved mixed forest, } \\
\text { coniferous forest, } \\
\text { deciduous broad- } \\
\text { leaved shrub, } \\
\text { shrub grass, } \\
\text { bamboo forest } \\
\text { deciduous broad-leaved } \\
\text { forest, evergreen mixed } \\
\text { deciduous broad-leaved } \\
\text { forest, warm evergreen } \\
\text { coniferous forest, } \\
\text { evergreen shrub, evergreen } \\
\text { meadow }\end{array}$ & $\begin{array}{c}\text { Evergreen broad- } \\
\text { leaved forest, } \\
\text { warm coniferous } \\
\text { forest, seasonal } \\
\text { rain forest, rain } \\
\text { forest, water area }\end{array}$ \\
\hline $\begin{array}{c}\text { Classification } \\
\text { assignment }\end{array}$ & 1 & 3 & 5 & 7 & 7 \\
\hline
\end{tabular}

\section{Research method}

According to the vegetation type and land use type in the Chishui River Basin, the assessment of habitat sensitivity in the Chishui River Basin was classified into insensitive, mildly sensitive, moderately sensitive, highly sensitive and extremely sensitive (table 1). Among them, three levels, which means moderate sensitivity, high sensitivity and extremely sensitive were identified as ecological sensitive targets.

In the form of expression, in order to represent the identified ecologically sensitive targets more intuitively on the map, this paper proposes to adopt the form of "high level habitat sensitivity distribution map". Namely, the insensitive and mildly sensitive areas in the assessment map of habitat sensitivity that reflects the five levels obtained in the study were removed, and only the three levels of moderately sensitive, highly sensitive and extremely sensitive were retained in the map. In other words, the areas with higher sensitivity were also the ecological sensitive targets of the watershed.

\section{Results and analysis}

According to the analysis of land use types with a resolution of $30 \mathrm{~m}$ in Chishui River Basin (Figure 1), there are six land use types in the basin: arable land, forest land, shrub land, water bodies and water conservancy facilities land, building construction land, and swamp (Figure 1).

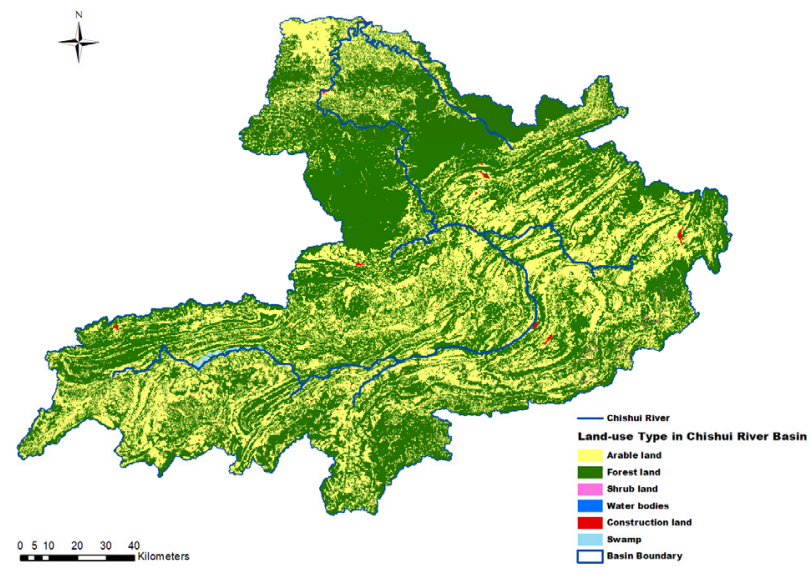

Figure 1 Land Use Type of Chishui River Basin (30 m resolution) 
We use ArcGIS to identify sensitive areas. The ecological sensitivity of arable lands and housing construction lands were considered as insensitive, accounting for $39.13 \%$ of the total basin area. The swamp was assigned as slightly sensitive level, accounting for $0.14 \%$ of the total area. Shrub land was identified as moderately sensitive, accounting for $0.10 \%$ of the basin area. Forest land identification was highly sensitive, accounting for $60.43 \%$ of the total area. Water bodies and water conservancy facilities land identification was extremely sensitive, accounting for $0.19 \%$ of the total basin area (table 2 and figure 2). And the ecological sensitive target of Chishui River Basin is the region with high sensitivity, as shown in Figure 3.

Table 2. The area percentage of different habitat sensitivity level in Chishui River Basin

\begin{tabular}{|c|c|}
\hline Habitat sensitivity level & Percentage \% \\
\hline insensitive & 39.13 \\
\hline slightly sensitive & 0.14 \\
\hline moderately sensitive & 0.10 \\
\hline highly sensitive & 60.43 \\
\hline extremely sensitive & 0.19 \\
\hline
\end{tabular}

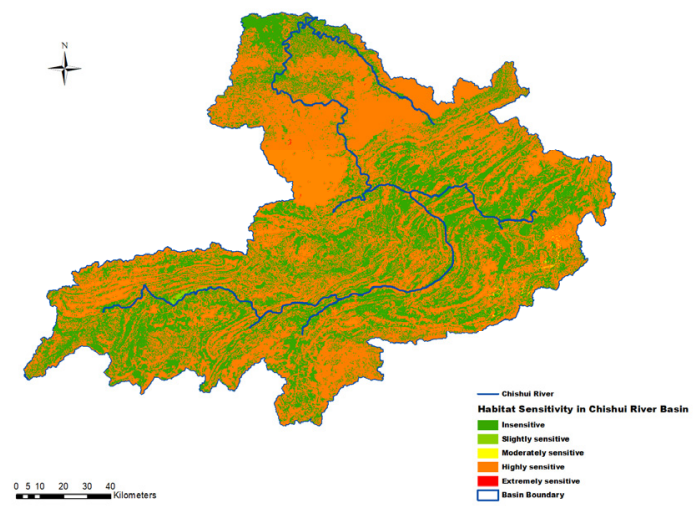

Figure 2 The Habitat sensitivity classification in Chishui River Basin

In order to represent the identified ecologically sensitive targets more intuitively on the map, the insensitive and mildly sensitive areas were removed in this paper, and only the three levels of moderately sensitive, highly sensitive and extremely sensitive are retained in the map, i.e. the areas with higher sensitivity are also ecologically sensitive targets of the watershed, forming a high level habitat sensitivity distribution map, as shown in Figure 3.

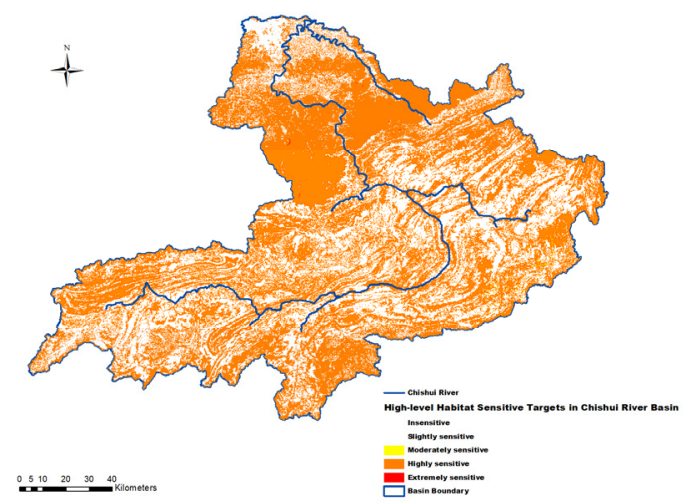

Figure 3. The identification of sensitive targets - the distribution of high-level habitat sensitive areats in Chishui River Basin

The evaluation results showed that the habitat sensitivity in Chishui River Basin was mainly in insensitive and highly sensitive areas. They account for more than $99.5 \%$ of the total basin area. The insensitive areas accounted for $39.13 \%$ and were widely distributed in the whole basin. The highly sensitive areas accounted for $60.43 \%$ of the basin area and were concentrated in the mountainous areas at the junction of Chishui City, Xishui County and Gulin County. The rest are widely distributed in the whole basin and inlaid with insensitive areas. Other mildly sensitive areas, moderately sensitive areas and extremely sensitive areas account for about $0.5 \%$ of the basin area, and there are a small number of them distributed in the whole basin, and the distribution is scattered. The moderate and above sensitive areas exceeded the basin area by $60.7 \%$, indicating that the overall habitat sensitivity was relatively sensitive, and the ecological sensitive targets were mainly woodland areas, which needed to be further protected.

\section{Conclusions}

In this paper, a sensitivity assessment system of ecosystem in Chishui River Basin based on biodiversity conservation is established by using GIS or RS spatial analysis techniques, and the conservation objectives of ecosystem in different regions are identified. The result shows that the habitats in the Chishui River Basin are generally more sensitive. The moderately sensitive areas exceed $60.7 \%$ of the basin area, and the highly sensitive areas account for $60.43 \%$ of the basin area, mostly concentrated in the mountainous areas at the junction of Chishui City, Xishui County and Gulin County. Among the six types of land use in the Chishui River Basin, there are arable land, forest land, shrub land, water bodies and water conservancy facilities land, building construction land, and swamp, the ecologically sensitive targets are mainly wooded areas, which need to be protected. The study points out the habitat sensitive areas in the Chishui River Basin, which provides a scientific basis for biodiversity protection and ecological civilization construction in this region. 


\section{Acknowledgements:}

This study was jointly funded by the National Natural Science Foundation of China (Grant No. 52079148), the scientific research projects of China Three Gorges Corporation (SD0203A012015, SD0203A032015) and the Scientific Research Special Project of China Institute of Water Resources and Hydropower Research (SD0145B302016), and we would like to thank them.

\section{References}

1. Z. Huang, The free flowing Chishui River- a unique and valuable river in the upper reaches of the Yangtze River. China Three Gorges Construction, 14(3): 1019 (2008).

2. Z. Huang, On the development and conservation for the resources and ecology of Chishui River Basin. Resources and Environment in the Yangtze Basin, 12(4): 332-339 (2003).

3. J. Pan, X. Dong, GIS-based Assessment and Division on Eco-environmental Sensitivity in the Heihe River Basin. Journal of Natural Resources, 21(2): 267-273 (2000).

4. J. Lin, W. Pan. Study on watershed Eco sensitivity Assessing and Regional Planning Based on GIS. Safety and Environmental Engineering, 12(2): 23-26, 34(2005).

5. L. Wang, The Study of Area Prone to Partition Geological Disaster in Guizhou Chishui River Basin Based on GIS. Master's Dissertation of Guizhou Normal University (2017).

6. X. Xiao, A. Lan, K. Xiong, Analysis on ecological environmental sensitivity of Xinjiang River Basin based on GIS. Yangtze River, 46(9): 68-72, 110 (2015).

7. Y. Chen, Sensitivity Analysis of River Basin Collapsed Gully Based on RS and GIS. Master's Dissertation of Fujian Normal University (2010).

8. Q.Ma, Sensitivity changes of Wuding River Basin in the north of Shanxi province in the past 10 years. Master's Dissertation of Northwest University (2013). 